\title{
Effect of Heat Flow, Precipitation and Evaporation on the Dynamics of the Marmara Sea Surface Waters
}

\author{
S.G. Demyshev, S.V. Dovgaya, M.V. Shokurov \\ Marine Hydrophysical Institute, Russian Academy of Sciences, Sevastopol, \\ Russian Federation \\ e-mail: demyshev@gmail.ru,dovgayasvetlana0309@yandex.ru,shokurov.m@gmail.com
}

\begin{abstract}
Dynamics of the Marmara Sea surface waters is investigated based on the high spatial resolution hydrodynamic model taking into account the atmospheric effect and the exchange through the straits of Bosporus and Dardanelles. The meteorological fields for 2008, obtained according to the calculation data of the MM5 regional atmospheric model are daily set on the sea surface. The features of seawater circulation induced by the heat flow, precipitation and evaporation above the surface of the basin are considered. Results of the numerical experiment are given being compared to the computation which takes into account only the wind forcing with zero heat flow, precipitation and evaporation on the sea surface. It is obtained that in winter under the negative surface density of the heat flow with intense evaporation in the southeastern sea part and precipitation over the northern one the conditions for the increase of gradient in the density field across the water current from the Bosporus to the Dardanelles are formed.

It is revealed that the conditions for generating a cyclonic eddy in the southeastern part of the basin and an anticyclonic one - in its northern part are formed in winter. In spring, at positive surface density of the heat flow and absence of precipitation and evaporation, the area of the central anticyclone increases. In autumn, when cold air masses intrude and the sea surface layer waters are still rather warm, a cyclonic vortex is formed in the southeastern part of the basin. Considerable effect of the atmospheric flows on the sea water dynamics is observed to $10-40 \mathrm{~m}$ depth.
\end{abstract}

Keywords: hydrophysical model, the Marmara Sea, circulation, anticyclone, cyclone, hydrophysical fields.

DOI: 10.22449/1573-160X-2016-3-3-13

(C) 2016, S.G. Demyshev, S.V. Dovgaya, M.V. Shokurov

(C) 2016, Physical Oceanography

Introduction. The Marmara Sea is an important element that affects the hydrology of the Black and Aegean Seas. The works [1, 2] represent the simplified box model of the Turkish straits system. It allows reproducing the general laws of the vertical water distribution. The numerical computations [3 -6], carried out by the present time on the basis of MHI model [7], show that the sea level field structure corresponds to the $S$-shaped current directed from the Bosporus to the Dardanelles; there is an extensive anticyclonic formation in the surface sea layer in the central part; the Aegean Sea water current is formed at $30 \mathrm{~m}$ depth, extending from the Dardanelles to the Bosporus. There is an anticyclonic vortex in the northern part of the sea and a cyclonic one - in the southern under the strong northeastern winds. But under the strong southwestern winds the vorticity signs in these parts of the sea are reversed. The ROMS model numerical solutions reproducing the general Marmara Sea circulation for the end of 2008 and February - March 2009 are given in [8]. This article shows that pycnocline displacement in the western part of the basin is influenced by the northeastern winds, while in the eastern one - the pycnocline response is determined by total effect of wind and the Bosporus water flow.

The present paper gives the analysis of the effect of the heat flow, precipitation and evaporation in 2008 on the dynamics of the Marmara Sea waters applying the

PHYSICAL OCEANOGRAPHY NO. 3 (2016) 
Pacanowski - Philander approximation for presentation on a vertical line the coefficients of turbulent exchange by an impulse and turbulent diffusion.

Problem formulation. The system of equations in the Boussinesq approximation, hydrostatic and sea water incompressibility is as follows ( $x$ and $y$ axes are directed to the east and north respectively, $z$ axis is directed vertically downwards):

$$
\begin{gathered}
u_{t}-(\xi+f) v+w u_{z}=-g \zeta_{x}-\frac{1}{\rho_{0}}\left(P^{\prime}+E\right)_{x}+\left(v_{V} u_{z}\right)_{z}-v_{H} \nabla^{4} u \\
v_{t}+(\xi+f) u+w v_{z}=-g \zeta_{y}-\frac{1}{\rho_{0}}\left(P^{\prime}+E\right)_{y}+\left(v_{V} v_{z}\right)_{z}-v_{H} \nabla^{4} v \\
P=g \rho_{0} \zeta+g \int_{0}^{z} \rho d \mu=g \rho_{0} \zeta+P^{\prime}, \\
u_{x}+v_{y}+w_{z}=0, \\
\zeta_{t}+\int_{0}^{H}\left(u_{x}+v_{y}\right) d z=(\operatorname{Pr}-\mathrm{Ev}) / \rho_{1}, \\
T_{t}+(u T)_{x}+(v T)_{y}+(w T)_{z}=-\kappa^{H} \nabla^{4} T+\left(\kappa^{T} T_{z}\right)_{z}, \\
S_{t}+(u S)_{x}+(v S)_{y}+(w S)_{z}=-\kappa^{H} \nabla^{4} S+\left(\kappa^{S} S_{z}\right)_{z} \\
\rho=\rho_{0}+\alpha_{1}^{T} T+\alpha_{1}^{S} S+\alpha_{2}^{T} T^{2}+\alpha^{S T} S T .
\end{gathered}
$$

Where $u, v$ and $w$ are components of velocity vector directed along $x, y$ and $z$ axes, respectively; $\xi=v_{x}-u_{y} ; E=\rho_{0}\left(u^{2}+v^{2}\right) / 2$; $\operatorname{Pr}$ is the velocity of precipitation; Ev is velocity of the water evaporation from the sea surface; $\rho_{1}$ is the average seawater density in the surface layer; $\alpha_{1}^{T}, \alpha_{1}^{S}, \alpha_{2}^{T}$ and $\alpha^{S T}$ are the known constants.

The equation (5) was obtained under the assumption that the linearized kinematic condition was performed in the form of $w=-\zeta_{t}+(\mathrm{Pr}-\mathrm{Ev}) / \rho_{1}$.

The coefficients of the vertical turbulent exchange by the impulse and vertical turbulent diffusion are calculated by the Pacanowski - Philander approximation [9]:

$$
\begin{gathered}
v_{V}=v_{0}^{V}\left(R_{0}+\mathrm{Ri}\right)^{-2}+v_{1}^{V}, \\
\kappa^{S}=\left[v_{0}^{S}\left(R_{0}+\mathrm{Ri}\right)^{-2}+v_{1}^{S}\right] /\left(R_{0}+\mathrm{Ri}\right)+\kappa_{1}^{S}, \\
\kappa^{T}=\left[v_{0}^{T}\left(R_{0}+\mathrm{Ri}\right)^{-2}+v_{1}^{T}\right] /\left(R_{0}+\mathrm{Ri}\right)+\kappa_{1}^{T},
\end{gathered}
$$

where $v_{0}^{V}, v_{0}^{S}, v_{0}^{T}, v_{1}^{V}, v_{1}^{S}, v_{1}^{T}$ and $R_{0}$ are the given constants; $\kappa_{1}^{S}, \kappa_{1}^{T}$ are the given functions; $\mathrm{Ri}=\left(g / \rho_{0}\right) \partial \rho / \partial z\left[(\partial u / \partial z)^{2}+(\partial v / \partial z)^{2}\right]^{-1}$ is the Richardson number.

If $v_{0}^{V}=v_{0}^{S}=v_{0}^{T}, v_{1}^{V}=v_{1}^{S}=v_{1}^{T}$ and $\kappa_{1}^{S}, \kappa_{1}^{T}$ are constants, the relations (9) (11) exactly correspond to the model of the vertical mixing from the paper [9].

When $z=0$ boundary conditions on the free surface for the system of equations (1) - (8) are as follows: 


$$
v_{V} u_{z}=-\tau^{x}, \quad v_{V} v_{z}=-\tau^{y}, \quad \kappa^{T} T_{z}=Q^{T}, \quad \kappa^{V} S_{z}=\frac{E v-\operatorname{Pr}}{\rho_{1}} S_{0},
$$

where $\tau^{x}, \tau^{y}$ are tangential wind stress components, $Q^{T}$ is a heat balance on the sea surface, $S_{0}$ is sea surface salinity.

The remaining notations are general. Tangential wind stress components $\tau^{x}, \tau^{y}$, total heat flow $Q^{T}$, velocity of the precipitation Pr, velocity of the water evaporation from the sea surface Ev are the aforementioned characteristics of atmospheric fields to be included in the hydrodynamic model as the boundary conditions.

The boundary conditions at the bottom under $z=H(x, y)$ are the following:

On the solid side walls:

$$
u=v=w=0, T_{z}=0, S_{z}=0 .
$$

- for the meridional boundary parts

$u=0, \nabla^{2} u=0, v_{x}=0, \nabla^{2} v_{x}=0, T_{x}=0,\left(\nabla^{2} T\right)_{x}=0, S_{x}=0,\left(\nabla^{2} S\right)_{x}=0$,

- for the zonal boundary parts

$v=0, \quad \nabla^{2} v=0, u_{y}=0, \nabla^{2} u_{y}=0, \quad T_{y}=0,\left(\nabla^{2} T\right)_{y}=0, S_{y}=0,\left(\nabla^{2} S\right)_{y}=0$.

In the parts of the boundary, where the water flows in (the Bosphorus upper layer and the Dardanelles lower layer), the Dirichlet conditions are used:

- for the meridional parts

$$
\begin{aligned}
& u=u^{s}, \nabla^{2} u=0, v_{x}=0, \nabla^{2} v_{x}=0, T=T^{s}, \quad S=S^{s},\left(\nabla^{2} T\right)_{x}=0,\left(\nabla^{2} S\right)_{x}=0 \text {, } \\
& \text { - for the zonal parts } \\
& v=v^{s}, \nabla^{2} v=0, u_{y}=0, \nabla^{2} u_{y}=0, T=T^{s}, S=S^{s}, \quad\left(\nabla^{2} T\right)_{y}=0,\left(\nabla^{2} S\right)_{y}=0 .
\end{aligned}
$$

In the parts of the boundary, where the water flows out (the Bosphorus lower layer and the Dardanelles upper layer), the following conditions are applied:

- for the meridional parts

$$
\begin{aligned}
& u=u^{s}, \nabla^{2} u=0, v_{x}=0, \nabla^{2} v_{x}=0, T_{x}=0, S_{x}=0,\left(\nabla^{2} T\right)_{x}=0,\left(\nabla^{2} S\right)_{x}=0, \\
& \quad \text { for the zonal parts } \\
& v=v^{s}, \nabla^{2} v=0, u_{y}=0, \nabla^{2} u_{y}=0, T_{y}=0, S_{y}=0,\left(\nabla^{2} T\right)_{y}=0,\left(\nabla^{2} S\right)_{y}=0 .
\end{aligned}
$$

The formulas (13) - (19) have the following notations introduced: $u^{s}$ and $v^{s}$ are horizontal velocities in the straits; $T^{s}$ and $S^{s}$ are temperature and salinity in the straits (the upper index s).

Initial fields were the temperature, salinity, horizontal velocities of the currents and the level fields, corresponding to the $18^{\text {th }}$ integration year for this model in the experiment without taking into account atmospheric effects.

The system of equations (1) - (8) having the corresponding boundary (12) (19) and initial conditions is solved numerically. The finite-difference discretization of the above model equations, boundary and initial conditions is carried out on a $C$-grid [10]. The used difference operators and features of an approximation of the model equations are presented in the works $[7,11]$.

Atmospheric effect. The fields of tangential wind stress, heat flow, precipitation and evaporation for 2008 are set daily on the sea surface. These fields were obtained according to the computation data of the regional atmospheric model 
MM5 (Fifth-Generation Penn State/NCAR Mesoscale Model, version 3.7) [12]. Now we are to consider the features of the atmospheric effect within the examined period. Since January to February the moderate negative surface density of the heat flow $Q^{T}$ (up to $-5 \cdot 10^{2} \mathrm{~W} / \mathrm{m}^{2}$ ) prevailed. Since the end of February to August the most of the sea area is dominated by warm air masses. The cold air invasion occurs at the beginning of September and lasts until the end of December accompanied with the periodic warm air entry on November $1-4$, and December $1-8$. The lowest temperature over this area is observed on February 16 - 19 with the surface density of the heat flow up to $-12 \cdot 10^{2} \mathrm{~W} / \mathrm{m}^{2}$ and the highest one - up to $4 \cdot 10^{2}$ $\mathrm{W} / \mathrm{m}^{2}$ is fixed on May $1-4$ and June $14-20$.

The greatest quantity of precipitation with the speeds up to $8 \cdot 10^{-5} \mathrm{~mm} / \mathrm{s}$ accounts for the following periods: mid-September - December and the third decade of January - March. As a rule, the wet air masses were the cyclones from the Mediterranean Sea. On April 26 - May 6, the region was influenced by the precipitation arrived from the Black Sea region.

Evaporation over the Marmara Sea with different intensity degree is observed from the beginning of January to the third decade of February and from the third decade of July to the end of the year. The air temperature in the region within these periods is less than the seawater surface temperature. The maximum evaporation is equal to $8 \cdot 10^{-5} \mathrm{~mm} / \mathrm{c}$. From late February to mid-July, when the air begins to warm up more intensely and its temperature exceeds the sea surface water temperature, there is practically no evaporation. The exception is the end of April, May $6-16$, and the first days of June, when there is the influence of the pretty cool (with the surface density of the heat flow up to $-10^{2} \mathrm{~W} / \mathrm{m}^{2}$ ) air masses. As for spatial distribution of intense evaporation areas on the Marmara Sea surface, all the winter months the high evaporation velocities are observed in the western part of the sea. This structure is due to the location of the cold air area with minimum temperatures over this basin part in the winter.

According to the available model data in the considered period the wind conditions over the Marmara Sea waters are characterized by the following features. The north-eastern winds are the most stable and repeatable in time and their gusts reach more than $14 \mathrm{~m} / \mathrm{c}$. Moderate winds of the same direction repeat almost throughout the year, except for March, May and December. Their duration is $3-10$ days. Southwestern winds also play a significant role in formation of the circulation of air masses over the sea. Their gusts in mid March reach more than $15 \mathrm{~m} / \mathrm{s}$. Such persistent winds prevail in March and April. Their duration is lasted 4 - 9 days. The mode of the atmospheric circulation in May and December is remarkably different. In May the cyclonic vorticity wind is replaced by the anticyclonic vorticity one (with the vorticity centers located to the north of sea basin). In December there is no explicit predominance of wind of any particular direction. In most cases, a change of the synoptic situation occurs after a period of gentle breezing.

The model parameters. The numerical computation was carried out under a horizontal resolution of $1.22 \mathrm{~km}$ along the $x$ axis and $0.83 \mathrm{~km}$ along the $y$ axis. 18 vertical horizons were used: $2.5 ; 5 ; 10 ; 15 ; 20 ; 25 ; 30 ; 40 ; 50 ; 62.5 ; 75 ; 100 ; 150$; 300; 500; 700; 900; $1100 \mathrm{~m}$. The time step in the model was $0.5 \mathrm{~m}$.

The velocities in the Bosporus and Dardanelles were set constant in time. They were calculated from specified discharges: $650 \mathrm{~km}^{3} /$ year - in the Bosporus 
upper layer $(0-20 \mathrm{~m}), 350 \mathrm{~km}^{3} /$ year - in its lower layer $(20-100 \mathrm{~m})$; $830 \mathrm{~km}^{3} /$ year - in the Dardanelles upper layer $(0-20 \mathrm{~m})$ and $530 \mathrm{~km}^{3} /$ year - in its lower layer $(20-75 \mathrm{~m})$ [2]. The upper layer temperature in the Bosporus was specified by taking into account its seasonal variability. The temperature values ranged within $8-23.5^{\circ} \mathrm{C}$ over time, the salinity ones - within $21-30 \%$ over depth [2]. According to the available measurement data, in the lower current of the Dardanelles at $20-75 \mathrm{~m}$ depth, the salinity was set in the range of $34.50-$ $38.68 \%$ and the temperature was equal to $14.6{ }^{\circ} \mathrm{C}$ [13].

Horizontally the coefficients of turbulent viscosity and diffusion took the following values, respectively:

$$
v_{H}=5 \cdot 10^{14} \mathrm{~cm}^{4} / \mathrm{s}, \quad \kappa^{H}=5 \cdot 10^{14} \mathrm{~cm}^{4} / \mathrm{s} .
$$

Parameters in the formulas (9) - (11) obtained on the basis of numerical experiments. Their results were compared with features of the interface location (known from the observations) of two basin water masses. Thus, in accordance with the in-situ measurements and model computations it was found that the section of the two water masses with different salinity occurred at $20-40 \mathrm{~m}$ depths and the drop in salinity $\Delta S$ was $9 \%$. In the formulas (9) - (11) the following parameter values were selected:

$$
v_{0}^{V}=v_{0}^{S}=v_{0}^{T}=30 \mathrm{~cm}^{2} / \mathrm{s}, v_{1}^{V}=5 \mathrm{~cm}^{2} / \mathrm{s}, v_{1}^{S}=v_{1}^{T}=1 \mathrm{~cm}^{2} / \mathrm{s} .
$$

Vertical position of the interface by upper and lower layers occurred to be close to the observed one, when the parameter $\kappa_{1}^{S}$ was equal to 2.8; $1.6 ; 0.4 ; 0.07$; 0.04 , and when $\kappa_{1}^{T}$ was equal to $0.9 ; 0.7 ; 0.5 ; 0.1 ; 0.05$ at depths up to $20 \mathrm{~m}$ for the horizons set above. $\kappa_{1}^{T}=\kappa_{1}^{S}=0.03 \mathrm{~cm}^{2} / \mathrm{s}$ were set below $20 \mathrm{~m}$.

Initial fields for $u, v, \zeta, T$ and $S$ corresponded to 6620 days (18.14 years), resulted from the integration of this model without taking into account the atmospheric effect [5].

Integration of equations of the model with the corresponding boundary and initial fields was carried out for one year.

The analysis results. We are to consider the features of the Marmara Sea water circulation, when under setting the heat, moisture and evaporation flows above the basin surface, the dynamic structures are distinctly marked. Results of the performed numerical experiment (Experiment 2) are compared with the computation where only the wind on the sea surface is taken into account [6] (Experiment 1).

Winter period. During the first decade of January there was the negative surface density of the heat flow up to $-5 \cdot 10^{2} \mathrm{~W} / \mathrm{m}^{2}$ observed above the sea surface. The evaporation velocity reached $3 \cdot 10^{-5}-5.5 \cdot 10^{-5} \mathrm{~mm} / \mathrm{s}$. Precipitation was intense on January $2-4$ (having velocity up to $7 \cdot 10^{-5} \mathrm{~mm} / \mathrm{s}$ ) and on 9 January (having velocity up to $3 \cdot 10^{-5} \mathrm{~mm} / \mathrm{s}$ ) in the north and northeastern parts of the basin. The sea level topography analysis showed, as compared with the Experiment 1 computation, the new anticyclonic eddy to form on January, 9 (Fig. 1, b). It had horizontal dimension of $30 \mathrm{~km}$ along the $x$ axis and $15 \mathrm{~km}$ along the $y$ axis with $10 \mathrm{~m}$ penetration depth and over $2 \mathrm{~cm}$ level increase. Its center is located approximately $28.4^{\circ}$ E. Comparison of Fig. $1, a$ and $1, b$ shows that area of the level decrease in the southeastern part of the sea became local and 
intense. This sea level decrease corresponds to the cyclonic eddy with $\sim 25 \mathrm{~km}$ diameter and $\sim 30 \mathrm{~m}$ penetration depth. The flow of water from the Bosporus to the Dardanelles narrowed and became a $S$-shaped current.

Fig. 2 shows the salinity fields for Experiment 1 (Fig. 2, $a$ ) and for Experiment 2 (Fig. 2, b) at $3 \mathrm{~m}$ horizon for January, 9. As a result of the evaporation, the water salinity of almost all the sea surface increased from $0.5 \%$ (in the Bosporus area) to $3 \%$ (to the southwest). In the southeastern part of the basin the increased salinity area was located. The difference $S$ from the periphery to the center (at $\sim 12.5 \mathrm{~km}$ distance) was $0.8 \%$ (Fig. 2).

Due to the presence of cold winter air in comparison with experiment 4, the surface water temperature decreased by $4-5{ }^{\circ} \mathrm{C}$, and was substantially homogeneous over the entire sea area, ranging from $10.5^{\circ} \mathrm{C}$ (in the eastern part of the basin) to $8.5{ }^{\circ} \mathrm{C}$ (in the west). Thus, taking into account the heat flows, evaporation and precipitation on January, 9, 2008 leads to the increase of the gradient in the density field across the current from the Bosporus to the Dardanelles. It reinforces the effect of advection and reduces contribution of the turbulent viscosity and diffusion. In its turn, the changed power balance provides the generation of cyclonic eddy in the southeastern part of the basin as a result of the influence of coastal orographic features on the jet current. Less dense water are pushed to the northern part of the basin, creating conditions for the formation of the anticyclonic vorticity. Depths of the distribution of the formed eddy structures are 10 - $30 \mathrm{~m}$. In accordance to Experiment 1 results such vortices are not observed.
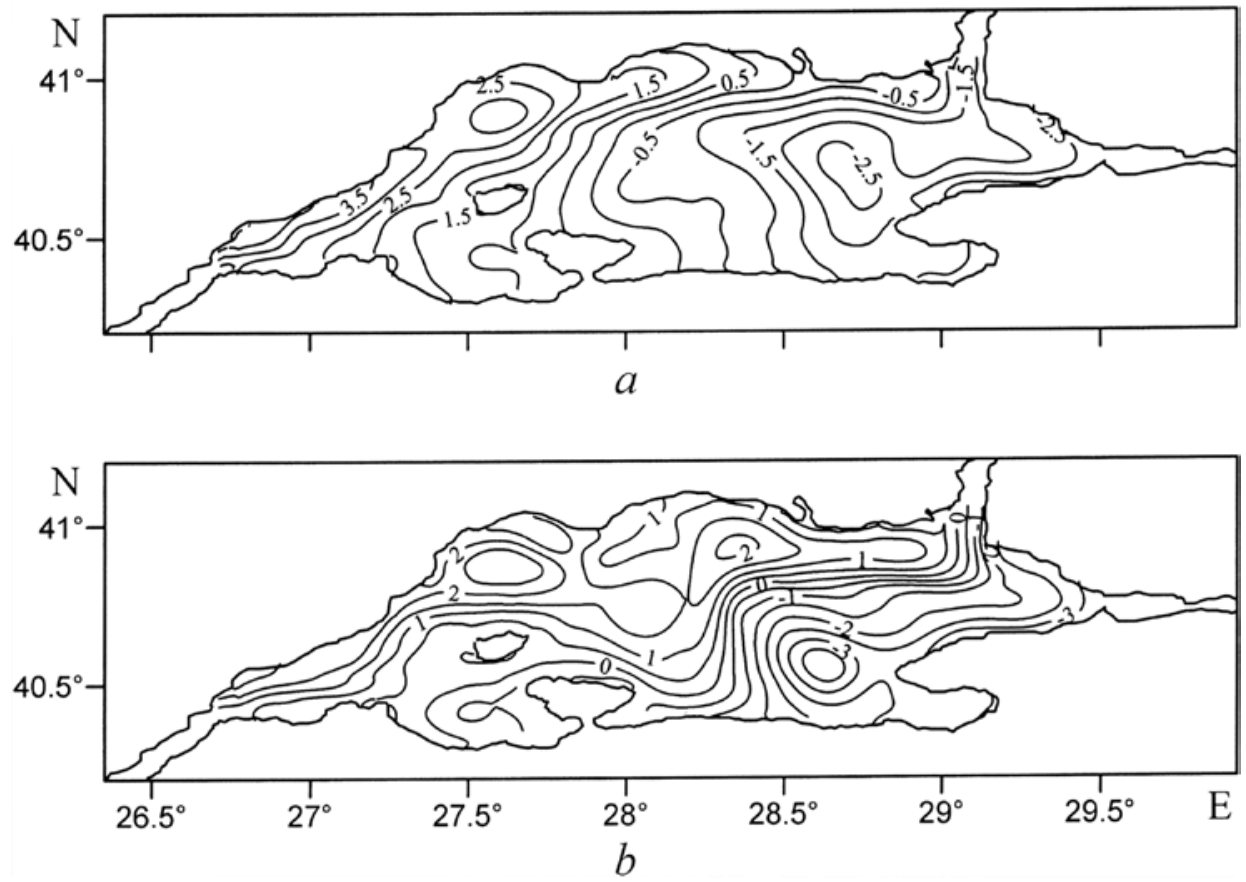

Fig. 1. Sea level topography (cm) on 9 January 2008 for Experiment 1 (a) and Experiment $2(b)$ 

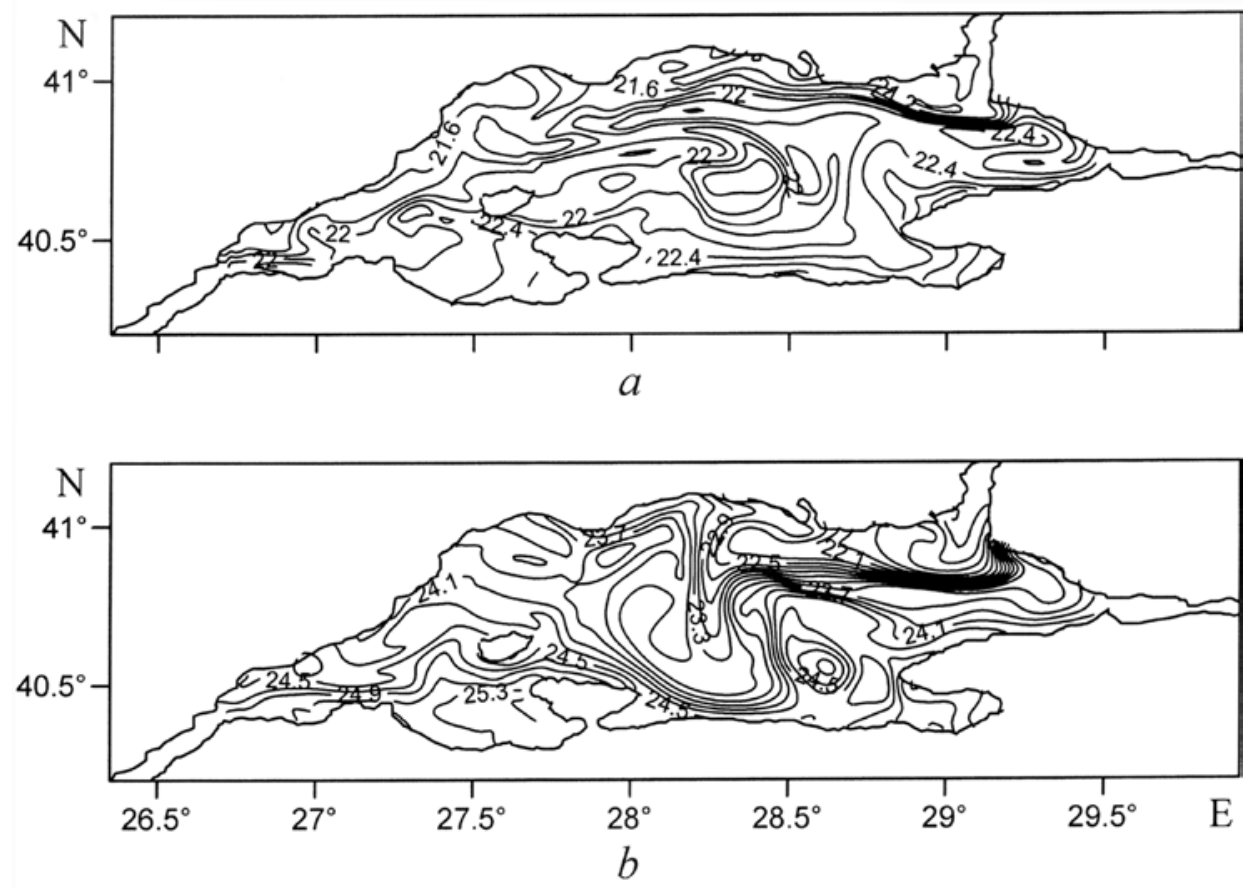

Fig. 2. Salinity fields (\%) at $3 \mathrm{~m}$ horizon on 9 January 2008 for Experiment $1(a)$ and Experiment $2(b)$

Spring episode. The role of accounting of heat flow in the circulation modeling of the Marmara Sea waters show the computation results for April 2008 (Fig. 3, 4 and 5). In this period from April 8 to 19 the surface density of the heat flow $Q^{T}$ was positive over the entire basin surface. It reached maximum values $\left(2 \cdot 10^{2} \mathrm{~W} / \mathrm{m}^{2}\right)$ over its central area, there was no precipitation, evaporation was observed from April, 16 to 19 along the sea perimeter, decreasing from coastal areas to the center (from $3 \cdot 10^{-5}$ to $6 \cdot 10^{-6} \mathrm{~mm} / \mathrm{s}$ ). In numerical experiment 2 , the propagation of the warm spring air masses over the cooled for winter sea surface led to a significant warming of the basin surface waters and the temperature increase by $1.5-7^{\circ} \mathrm{C}$ (Fig. 3, $a, b$ ).

The water salinity on April, 19 in the presence of the warm spring air over the water area increased by $1-1.4 \%$ (in comparison with Experiment 1 ). As a result of the substantial increase of the water temperature in in the central part of the sea (by $6-7^{\circ} \mathrm{C}$ ), the gradient in the density field across the streamlines of the central anticyclone decreases. Thus the influence of advection summands in the equations of motion decreases and contribution of the turbulent viscosity and diffusion increases. Consequently, the anticyclone becomes extensive (Fig. 4, $b ; 5, b$ ). The topography of the sea level and velocity field in the experiment without taking into account the heat, precipitation and evaporation flows are presented respectively in Fig. 4, $a$ and 5, $a$. According to the results of Experiment 1, the anticyclone was located in the Bosporus area and had $\sim 35 \mathrm{~km}$ diameter with $30 \mathrm{~m}$ penetration depth. While the results of Experiment 2 show its propagation area to increase by 
2 times (covering the entire eastern part of the basin), and to have the penetration depth up to $40 \mathrm{~m}$.
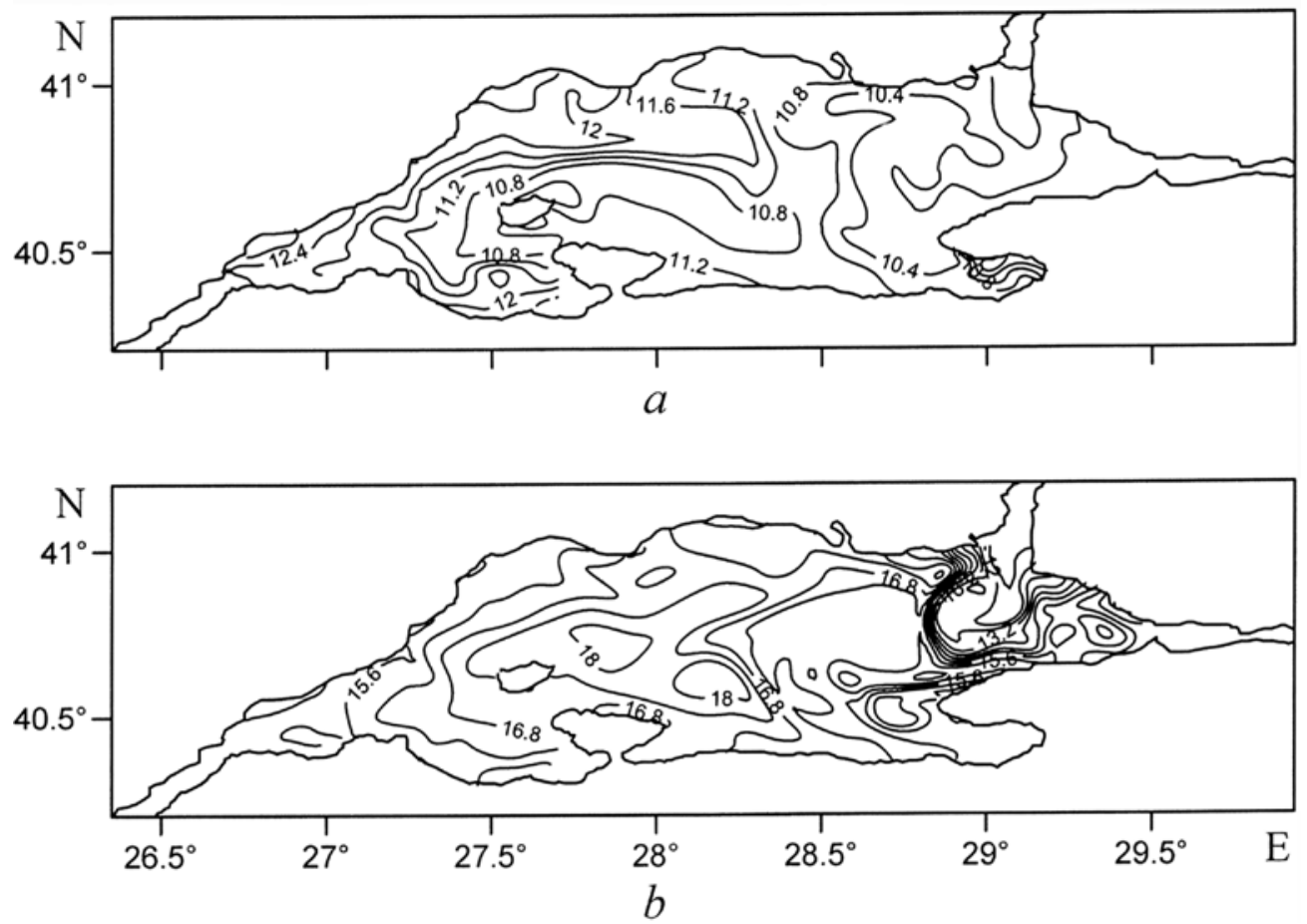

Fig. 3. Temperature fields $\left({ }^{\circ} \mathrm{C}\right)$ at $3 \mathrm{~m}$ horizon on 19 April 2008 for Experiment $1(a)$ and Experiment $2(b)$
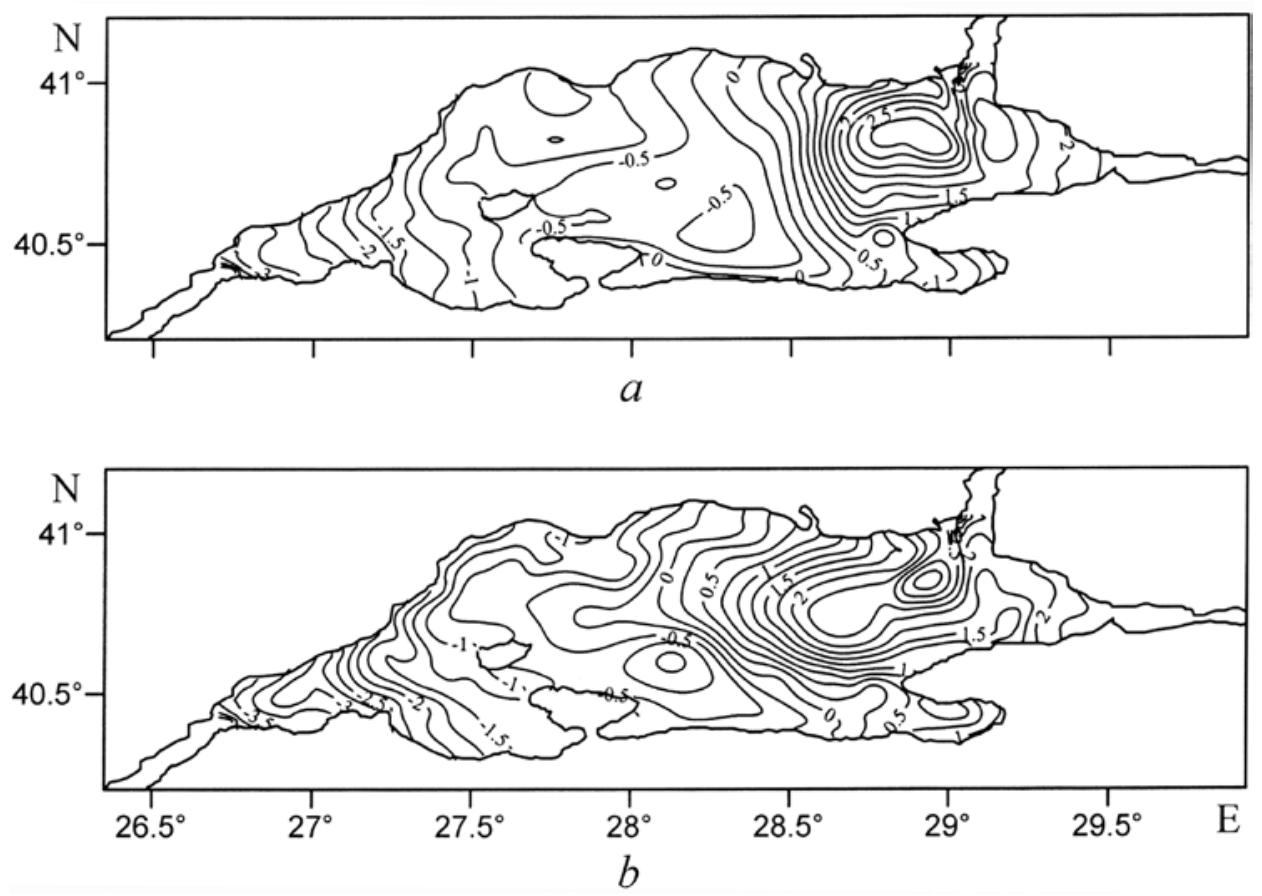

Fig. 4. Topography of the sea level (cm) on 19 April 2008 for Experiment $1(a)$ and Experiment $2(b)$ 10

PHYSICAL OCEANOGRAPHY NO. 3 (2016) 

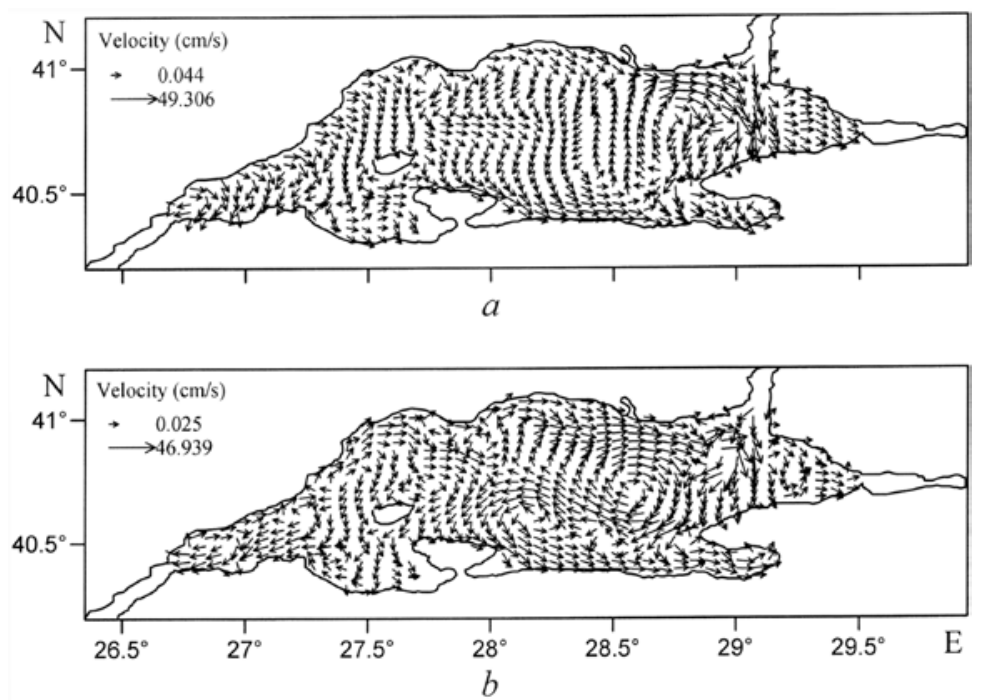

Fig. 5. Velocity (cm/s) at $3 \mathrm{~m}$ horizon on 19 April 2008 for Experiment 1 (a) and Experiment 2 (b)

Autumn episode. Considerable effect of water evaporation from the Marmara Sea surface on the propagation of current velocities in the upper layer is observed in the beginning of September. It is characterized by the entry of cold air masses in the presence of the sea surface layer quite warmed during the summer (Fig. 6, 7). Thus, within September $1-6$ period the negative values of the surface density of the heat flow (the minimum ones reached $-4 \cdot 10^{2} \mathrm{~W} / \mathrm{m}^{2}$ ) were marked. During this period, the evaporation with maximum velocities of up to $8 \cdot 10^{-5} \mathrm{~mm} / \mathrm{s}$ was observed over the entire basin surface. Also, there was no precipitation. Under such weather conditions in the southeast of the basin the cyclonic eddy had been formed by September, 6. It is not marked in Experiment 1. Fig. 6 shows a map of the salinity fields for September, 6 for the Experiment 1 (a) and for Experiment 2 (b). It is clear that a strong evaporation from the sea surface leads to surface water salinity increase of $0.3-2.7 \%$ all over the sea area.
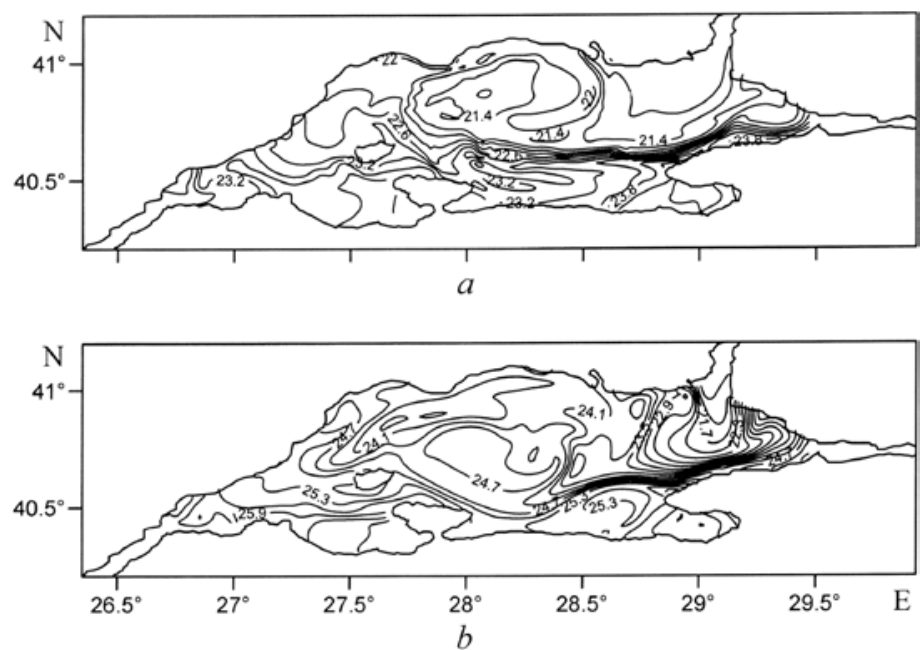

Fig. 6. Salinity fields (\%) at $3 \mathrm{~m}$ horizon on 6 September 2008 for Experiment $1(a)$ and Experiment $2(b)$

PHYSICAL OCEANOGRAPHY NO. 3 (2016) 

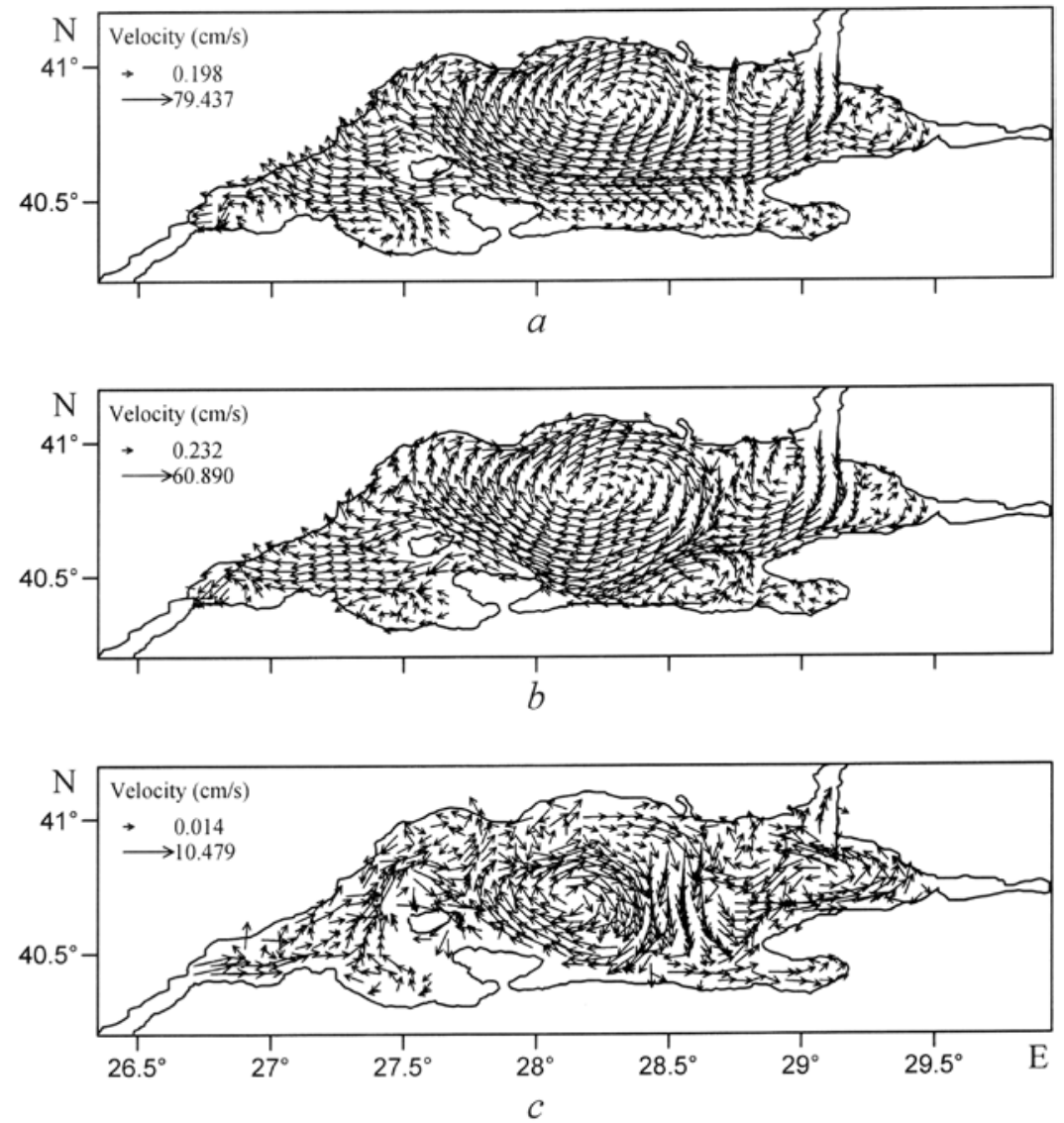

Fig. 7. Velocity $(\mathrm{cm} / \mathrm{s})$ on 6 September at $3 \mathrm{~m}$ horizon for Experiment $1(a)$ and Experiment $2(b)$ and also at $40 \mathrm{~m}$ horizon for Experiment 2 (c)

Conclusion. Thus, the experiment conducted showed the significant effect of the heat flow, precipitation and evaporation on the formation of dynamic structures in the Marmara Sea surface layer in 2008. So, in winter under the negative surface density of the heat flow with intense evaporation in the southeastern sea part and precipitation over the northern one the conditions for the increase of gradient in the density field across the water current from the Bosporus to the Dardanelles are formed. These conditions reinforce the effect of advection and provide the cyclonic eddy generation in the southeastern part of the basin and anticyclonic one - in the north.

In spring under the positive surface density of the heat flow and the absence of precipitation and evaporation the anticyclonic vortex area in the central part of the basin increases.

The presence of cool air and the heated sea water in the absence of precipitation in autumn creates the conditions for the cyclonic gyre formation in the southeastern part of the basin. Considerable effect of the atmospheric flows on the sea water dynamics is observed to $10-40 \mathrm{~m}$ depth. 


\section{REFERENCES}

1. Surku, T. Besiktepe, Emin, Ozsoy \& Umit, Unluata, 1993, "Filling of the Marmara Sea of the Dardanelles Lower Layer inflow”, Deep-Sea Res., no. 40, pp. 1815-1838.

2. Besiktepe Surku T., Sur Halil I. \& Ozsoy Emin [et al.], 1994, "The circulation and hydrography of the Marmara Sea”, Prog. Oceanog., no. 34, pp. 285-334.

3. Demyshev, S.G., Dovgaya, S.V., 2007, "Chislennyy eksperiment po modelirovaniyu gidrofizicheskikh poley Mramornogo morya s uchetom prolivov Bosfor i Dardanelly [Numerical experiment on modeling of the Marmara Sea hydrophysical fields taking into account the Bosporus and the Dardanelles]”, Morskoy gidrofizicheskiy zhurnal, no. 3, pp. 2842 (in Russian).

4. Demyshev, S.G., Dovgaya, S.V., 2010, "Struktura termokhalinnykh poley vod Mramornogo morya [The structure of the thermohaline fields of the Marmara Sea waters]", Sistemy kontrolya okruzhayushchey sredy, iss. 14, pp. 107-110 (in Russian).

5. Demyshev, S.G., Dovgaya, S.V. \& Ivanov, V.A., 2012, “Chislennoe modelirovanie vliyaniya obmena cherez prolivy Bosfor i Dardanely na gidrofizicheskie polya Mramornogo morya [Numerical modeling of the exchange through the Bosporus and the Dardanelles on the Marmara Sea hydrophysical fields]”, Izv. RAN. Fizika atmosfery i okeana, vol. 48, no. 4, pp. 418-426 (in Russian).

6. Demyshev, S.G., Dovgaya, S.V., 2014, “Chislennoe modelirovanie tsirkulyatsii Mramornogo morya $v 2008$ godu s uchetom vetra i vodoobmena cherez prolivy Bosfor i Dardanelly [Numerical modeling of the Marmara Sea circulation in 2008 taking into account the wind and the water exchange through the Bosporus and the Dardanelles]", Morskoy gidrofizicheskiy zhurnal, no. 1, pp. 68-79 (in Russian).

7. Demyshev, S.G., Korotaev, G.K., 1986, “Chislennaya konservativnaya model' baroklinnykh techeniy $v$ okeane [Numerical conservative model of baroclinic currents in the ocean]", Chislennoe modelirovanie klimata Mirovogo okeana, pp. 60-79 (in Russian).

8. Chiggiato, J., Jarosz, E. \& Book, J.W. [et al.], 2012, "Dynamics of the circulation in the Sea of Marmara: numerical modeling experiments and observations from the Turkish straits system experiment”, Ocean Dyn., no. 62, pp. 139-159.

9. Pacanowski, R.C., Philander, S.G.H., 1981, "Parameterization of vertical mixing in numerical models of tropical oceans”, J. Phys. Oceanogr., vol. 11, no. 11, pp. 1443-1451.

10. Arakava, A., 1966, "Computational design for long-term numerical integration of the equations of fluid motion: Two-dimensional incompressible flow”, J. Comput. Phys., no. 1, pp. 119-143.

11. Demyshev, S.G., 1996, "O povyshenii tochnosti rascheta techeniy $v$ Chernom more pri ispol'zovanii privedennogo urovnya $v$ chislennoy modeli [On increasing the accuracy of the calculation of the Black Sea currents using the given level in the numerical model]", Meteorologiya i gidrologiya, no. 9, pp. 75-83 (in Russian).

12. http://www.ucar.edu/mm5/mm4/home.html (access date 10.12.2014).

13. Zapevalov, A.S., 2005, “Sezonnaya izmenchivost' vertikal'nykh raspredeleniy temperatury $i$ solenosti $v$ Mramornom more [Seasonal variability of the vertical distribution of temperature and salinity in the Marmara Sea]”, Meteorologiya i gidrologiya, no. 2, pp. 78-84 (in Russian). 